\title{
Medidas laborales y de seguridad social ante la emergencia provocada por el covid-19: La experiencia española
}

\author{
Labour and social security measures to deal with the emergency \\ caused by covid-19: The spanish experience
}

\author{
Iván Antonio Rodríguez Cardo iD \\ Universidad de Oviedo, España
}

\begin{abstract}
RESUMEN El covid-19 ha provocado una pandemia mundial que, además del impacto sanitario, ha menoscabado sustancialmente la situación social y económica. La repercusión en España no ha sido menor, como lo demuestra el recurso del gobierno de un mecanismo previsto en la Constitución ante situaciones de emergencia: el llamado estado de alarma, que confiere al Ejecutivo poderes extraordinarios dirigidos, en este caso, a evitar la propagación de la enfermedad. Las medidas adoptadas, aunque siempre con la finalidad de protección de la salud pública, han afectado derechos fundamentales de las personas (el confinamiento conlleva una limitación de la libertad de movimiento) y han repercutido en la marcha de la economía, por la reducción -e incluso paralización - temporal de la actividad económica de carácter no esencial. Estas medidas implicaban, por tanto, la imposibilidad de continuar prestando servicios para muchos trabajadores o cambios relevantes en las condiciones de trabajo. Por esto, el gobierno aprobó un paquete de medidas de urgencia en el ámbito de lo laboral y de la seguridad social, entre las que se incluía la promoción del teletrabajo, una mayor flexibilidad interna para facilitar modificaciones en materia de jornada y horarios, nuevos derechos de conciliación de la vida laboral y familiar, y unos procedimientos más expeditos en orden a que las empresas pudieran decidir reducciones de jornada y suspensiones de contratos por esta situación tan particular provocada por la pandemia. No cabe duda de que los poderes empresariales se han visto potenciados, ya que uno de los objetivos prioritarios de estos ajustes consistía en asegurar que la actividad económica pudiera reanudarse, en las mejores condiciones posibles, tras el estado de alarma. Ahora bien, asimismo, se introdujeron contrapesos para proteger los intereses del trabajador, como la prohibición temporal de despidos por causas empresariales o una mejora evidente de la protección por desempleo en el ámbito de la seguridad social. Este estudio trata de aportar una panorámica tanto general como sistemática sobre todas las medidas de carácter laboral y social adoptadas en España durante el estado de alarma.
\end{abstract}


PALABRAS CLAVE Covid-19, estado de alarma, teletrabajo, suspensión de contrato, reducción de jornada, fuerza mayor, despido, seguridad social.

\begin{abstract}
The covid-19 pandemic has had a great impact in Spain. With the purpose of slowing down the spread of the virus and controlling the situation, the government declared the state of alarm and imposed restrictions to people's movement and social contact (including temporary confinement of the population at home). Most economic and working activities were temporarily paralysed, leaving apart those considered «essential services» and other exceptions. With the aim of reducing the economic and social impact of such extraordinary circumstances, protecting workers and allowing to resume working activities after the crisis, the government approved a package of urgent legislation, including a large list of measures in the area of Labour Law and Social Security: among others, promoting telework; facilitating the adaptation of working time to family care needs; favouring the temporary suspension of employment contracts or the reduction of working time due to force majeure or other grounds related to covid-19, while dismissals were limited; establishing an extraordinary paid leave for workers of undertakings forced to stop their activity; finally, adapting and enhancing unemployment benefits and other forms of social protection. This paper provides a panoramic explanation on this legislation aiming to face the covid-19 health, economic and employment crisis.
\end{abstract}

KEYWORDS Covid-19, state of alarm, telework, temporary suspension of employment contracts, temporary reduction in working hours, force majeure, dismissals, social security benefits.

\title{
Introducción
}

La epidemia mundial, provocada por el coronavirus, ha obligado a implementar numerosas medidas dirigidas a evitar su propagación y proteger la salud de las personas. Muchas de estas repercuten en los derechos fundamentales de los individuos, lo que explica que se hayan adoptado en un contexto de excepcionalidad jurídica y social, cuyos efectos han alcanzado las relaciones de trabajo, requiriendo una modulación de los derechos y obligaciones laborales para acomodarse a una situación, hasta ahora, desconocida.

En España, el punto de partida puede situarse el 14 de marzo de 2020, cuando el gobierno declaró el estado de alarma, una de las tres posibilidades (junto a los estados de excepción y de sitio) que ofrece el artículo 116 de la Constitución para afrontar situaciones de gravedad que exijan activar resortes poco comunes $\mathrm{y}$, desde luego, no deseados. ${ }^{1}$ Ese marco normativo extraordinario ha supuesto, en primer lu-

1. La Constitución española puede consultarse en bit.ly/3lgjkbw. Los estados de alarma, excepción y sitio se encuentran regulados en la Ley Orgánica 4/1981 del 1 de junio, que puede consultarse en bit. 
gar, una restricción de los derechos individuales de movilidad y desplazamiento, con el propósito de limitar el contacto entre personas y disminuir las posibilidades de contagio. Se trata de medidas heterogéneas, con ámbitos materiales e intensidades muy diferentes. Por ejemplo, han derivado en un cierre de fronteras que, en otro contexto, sería contrario al derecho de la Unión Europea, ${ }^{2}$ y también en una restricción de movilidad interna que no solo significaba la prohibición de desplazamientos entre provincias y regiones, sino el confinamiento de las personas que, únicamente, con causa justificada (como acudir al trabajo o hacer la compra) y/o en horarios prefijados, podían abandonar su domicilio.

Desde una perspectiva más económica y laboral, la declaración del estado de alarma supuso, en primer término, la suspensión de toda actividad comercial, cultural, de ocio o deportiva, así como de hostelería y restauración (salvo servicios a domicilio). Otras, como las educativas, podían continuar, pero no de forma presencial. En verdad, esa se convertiría en una recomendación legal de carácter general, ya que las normas aconsejaban priorizar el teletrabajo donde fuera posible. ${ }^{3}$

La evolución de la pandemia, con un incremento significativo tanto del número de contagios como de fallecidos, y una aparente escasez de medios y recursos sanitarios, propició que el 29 de marzo, mediante el Real Decreto-Ley 10/2020, ${ }^{4}$ se iniciase una segunda etapa más restrictiva que la anterior, porque fueron suspendidas todas

ly/3fHoDxV. Conforme a esta normativa, el gobierno puede declarar el estado de alarma durante un período inicial de 15 días, aunque se admiten prórrogas, pero ha de contar con la autorización del Parlamento. El propósito del estado de alarma consiste en afrontar consecuencias derivadas de las siguientes situaciones: «a) catástrofes, calamidades o desgracias públicas, como terremotos, inundaciones, incendios urbanos y forestales o accidentes de gran magnitud; b) crisis sanitarias, como epidemias y situaciones de contaminación graves; c) paralización de servicios públicos esenciales para la comunidad, cuando no se garantice lo dispuesto en los artículos veintiocho, dos, y treinta y siete, dos, de la Constitución, y concurra alguna de las demás circunstancia o situaciones contenidas en este artículo; d) situaciones de desabastecimiento de productos de primera necesidad». El estado de alarma permite al gobierno asumir competencias que de ordinario corresponden a las comunidades autónomas, así como tomar medidas que en otros contextos serían contrarias a la Constitución, como la limitación de la libertad de circulación de las personas o de la permanencia en horas y lugares determinados, la requisa temporal de bienes, la imposición de prestaciones personales obligatorias, la intervención temporal de industrias, fábricas o negocios de cualquier índole, la limitación del uso de servicios o del consumo de artículos de primera necesidad, así como aprobar o imponer órdenes y reglas para asegurar el abastecimiento de productos básicos. No obstante, el hecho de que el Gobierno pueda ejercer facultades más intensas no implica un poder ilimitado, sino que es una situación temporal que además debe ajustarse a las premisas constitucionales. Es conveniente destacar que durante el estado de alarma los derechos fundamentales no están suspendidos, ni se ve alterada la configuración de las instituciones democráticas.

2. Para más información, véase la Orden INT/239/2020 del 16 de marzo, disponible en bit.ly/3fAMr6r.

3. Para más información, véase el Real Decreto 463/2020 del 14 de marzo, disponible en bit. ly/3mdRdJW.

4. Para más información, véase bit.ly/3fCEGo8. 
las actividades de carácter no esencial hasta el 9 de abril, lo que suponía, en definitiva, paralizar el sector industrial durante dos semanas, salvo aquellas actividades que pudieran realizarse a distancia. Con este fin, el gobierno se sirvió de una alternativa imaginativa: un permiso retribuido obligatorio. Así, la empresa debía continuar abonando el salario al trabajador en ese período, pero las horas no trabajadas deberían recuperarse durante 2020, aunque el modo concreto se remitía a una negociación entre los representantes de los trabajadores y el empresario. Esta norma dejaba claro que la duración del estado de alarma se extendería en el tiempo más de lo previsto inicialmente, pero que la intensidad de las restricciones a la movilidad y a la actividad económica debían variar en atención a la evolución de la pandemia.

En efecto, el estado de alarma fue extendido cada 15 días hasta el 21 de junio de 2020 (de modo que su duración se prolongó más de tres meses), momento en el que se inició la denominada "nueva normalidad". Un análisis detenido permite aseverar que el estado de alarma ha demostrado ser una figura poliédrica de una notable flexibilidad, como se aprecia en las reglas del Plan de transición a la nueva normalidad, más conocido con el nombre de «desescalada», cuya finalidad consistía en compatibilizar la progresiva eliminación de las restricciones con la eficaz contención de la pandemia, lo que derivó en una asimetría entre regiones y territorios en función del impacto del covid-19 en cada uno de ellos.

Sea como sea, la actividad económica se resintió notablemente durante el estado de alarma, bien por la suspensión de actividades decidida por el gobierno o, indirectamente, por las consecuencias naturales de las restricciones a la movilidad. Un alto porcentaje de empresas y negocios sufrieron una paralización total de su actividad o, como mínimo, una reducción muy notable de su volumen de negocio, lo que desembocó en la adopción de medidas de ajuste de plantilla con un amplio abanico a disposición del empleador, al menos teóricamente, ya que la legislación laboral permitía desde una respuesta coyuntural y con perspectivas más favorables para el mantenimiento del empleo (reducción temporal de jornada) hasta otras mucho más traumáticas, inclusive el despido.

No obstante, desde el primer momento, el gobierno decidió intervenir para proporcionar reglas específicas que permitieran afrontar una problemática que ha afectado a más de tres millones de trabajadores. Así, el 17 de marzo fue aprobado el Real Decreto-Ley 8/2020, ${ }^{5}$ que llevó por título «De medidas urgentes extraordinarias para hacer frente al impacto económico y social del covid-19", y contempló reglas particulares en el contexto laboral, especialmente en relación con decisiones empresariales sobre la reducción de jornada o la suspensión de contratos. Esa norma fue modificada en varias ocasiones durante el estado de alarma. Además, fue complementada por muchas otras, como, por ejemplo, el Real Decreto-Ley 9/2020 del 27 de marzo, en el

5. Para más información, véase bit.ly/33k5zRj. 
que se contenían medidas de diferente signo para proteger el empleo y aminorar, en lo posible, el impacto negativo de la crisis para los trabajadores. Entre ellas destaca, sin lugar a dudas, la prohibición de despidos por causas económicas, organizativas, técnicas o de producción, o por fuerza mayor, durante el estado de alarma (aunque, como se verá, se ha extendido más allá), ya que debía priorizarse, en lo posible, la pervivencia del empleo. ${ }^{6}$

Desde la perspectiva de las fuentes del derecho, la situación ha resultado ciertamente peculiar, porque la legislación laboral ordinaria seguía vigente y, desde luego, proporcionaba $-\mathrm{y}$ proporciona- herramientas para afrontar tanto la crisis de empresa como las restructuraciones de plantilla. Se trata de reglas con un bagaje notable, elaboradas en otros contextos muy problemáticos, que resultan conformes con el derecho de la Unión Europea y que han sido oportunamente depuradas e interpretadas por los tribunales. Sin embargo, el covid-19 dio lugar a un contexto muy particular al que esas reglas no se acomodaban bien, porque, en sentido estricto, no se producía una crisis de empresa, sino restricciones o limitaciones impuestas por los poderes públicos que afectaban a negocios plenamente viables en circunstancias ordinarias. Las empresas afectadas no se encontraban en crisis o en dificultades antes de la pandemia, y teóricamente deberían poder retomar sus actividades con posterioridad. El marco normativo debía permitir un tránsito lo más apacible posible por esa situación coyuntural (Álvarez García, 2020: 10-14).

Con ese fin, el gobierno aprobó una amplia panoplia de reglas y medidas — convalidadas después por el Parlamento- que el Boletín Oficial del Estado incluyó en un "Código» actualizado diariamente. ${ }^{7}$ Se trata de medidas de diferente calado, todas ellas relacionadas con el peculiar contexto generado por el covid-19 y, entre las que tienen una significación especial, las conectadas tanto con la protección de los trabajadores como con el apoyo a las empresas para que puedan continuar con su actividad y mantener el nivel de empleo. De alguna forma, se trata de un "paquete legislativo de emergencia» para afrontar el impacto en el empleo de la pandemia, cuya aprobación no se ha basado en una planificación a largo plazo, sino en atender a los problemas más urgentes según se fueran suscitando en un escenario sin precedentes y cuyas consecuencias no parecían fácilmente previsibles.

Muchas de esas reglas fueron concebidas con una duración limitada, de modo que su ámbito temporal de aplicación habría de coincidir con la pervivencia de las circunstancias extraordinarias que justificaron su aprobación. Sin embargo, muchas de ellas han sido prorrogadas en varias ocasiones con el propósito de facilitar el mantenimiento del empleo, de modo que su vigencia se ha extendido hasta 31 de enero de 2021, pero

6. Para más información, véase el Real Decreto-ley 9/2020, de 27 de marzo, disponible en bit. ly/2HBOoVg.

7. Para más información, véase bit.ly/2JaZQGu. 
no se descartan nuevas prórrogas, ya que, desde el 25 de octubre de 2020. España se encuentra nuevamente en estado de alarma para hacer frente a la pandemia.

Como se decía, desde la perspectiva de las fuentes del derecho se han producido anomalías, porque esta legislación de emergencia ha creado, de algún modo, un derecho del trabajo "paralelo», diferente al ordinario, y que ha coexistido $-\mathrm{y}$ coexiste- con él durante este particular período de tiempo en el que la pandemia ha activado resortes jurídicos desconocidos y, de algún modo, improvisados. Por lo tanto, durante estos meses, ha tenido lugar un fenómeno jurídico peculiar, ya que han estado vigentes dos regulaciones laborales diferentes. Por un lado, está el derecho del trabajo más tradicional, incluido principalmente en el Estatuto de los Trabajadores. ${ }^{8}$ Por otro lado, está la normativa de emergencia, que parcialmente desplaza el derecho del trabajo estructural en tanto subsistan los efectos de la pandemia. Estas reglas extraordinarias tienen una vocación coyuntural, hasta el punto de que muchas de ellas ni siquiera estaban previstas para toda la duración del estado de alarma, como quedó de manifiesto con las fases de la «desescalada».

Aparentemente, muchas de las medidas de emergencia temporales aprobadas durante el estado de alarma no han de suponer, hacia el futuro, una modificación estructural del derecho del trabajo en materias como el tiempo destinado a él o las suspensiones y extinciones de contratos. En tanto que atienden a una situación de emergencia, se justifican exclusivamente en ese escenario y no en otros sin esas particularidades. No obstante, resulta prematuro descartar un impacto futuro relevante de alguna de esas actuaciones. De hecho, las negociaciones entre los agentes sociales y el gobierno parecen apuntar a que el teletrabajo recibirá un impulso sustancial en un futuro próximo a través de un nuevo marco normativo que, parece, tratará de promocionarlo, ya que, hasta el momento, la preferencia social y empresarial por el trabajo presencial ha relegado al teletrabajo a un plano menor, y solo se recurre a dicha fórmula cuando la presencialidad no es posible, de modo que no se configura como alternativa al trabajo ordinario, sino como excepción derivada de la necesidad.

Precisamente, en clave jurídico-laboral esta es una de las conclusiones que quizá puedan extraerse de la crisis sanitaria, ya que el teletrabajo se ha convertido en una alternativa - forzada - al trabajo presencial. Es probable que la organización del trabajo experimente cambios significativos en algunos sectores durante los próximos años debido a las tecnologías de la información y la comunicación, y el derecho del trabajo deberá afrontar esos retos, que no solo repercuten en la manera de organizar el trabajo, sino, desde luego, también en el modo de organización vital de las personas, por lo que esas reglas — principalmente las que atañen al teletrabajo- habrán de

8. Para más información, véase el Real Decreto Legislativo 2/2015 del 23 de octubre, disponible en bit. ly/3183E8o. 
tener muy presente el derecho a la conciliación de la vida personal y familiar, que ha sufrido debido al cese de actividades de los centros educativos o de guarderías.

En cualquier caso, la mayor relevancia del teletrabajo no es la única lección que cabe extraer de la crisis provocada por el covid-19. Desde una perspectiva de política legislativa, debe destacarse, sin género de dudas, el protagonismo principal que ha asumido el gobierno, que, con el apoyo del Parlamento, ha aprobado un ingente conjunto de normas sin contar con el diálogo social, amparándose en la urgencia. Por tanto, en tiempos de crisis, los poderes públicos se consideran legitimados para intervenir de forma directa y unilateral, aunque esto implique reducir la autonomía individual y colectiva en muchos ámbitos, también el laboral.

En el ejercicio de ese liderazgo, el gobierno ha dedicado sus mayores esfuerzos a proteger el empleo a largo plazo, priorizando medidas de ajuste laboral que no impliquen la extinción de contratos. Entre ellas, destacan las reducciones de jornada y las suspensiones de contratos, que han venido acompañadas de modificaciones en el ámbito de la seguridad social para proporcionar ingresos sustitutivos a los trabajadores que se ven afectados por esas medidas laborales, que si bien no suponen una extinción del contrato, sí implican una reducción o pérdida temporal del salario. En fin, también conviene recordar que la mayor parte de estas actuaciones se han dirigido al sector privado, y que el empleo público se ha visto menos perjudicado, en particular en lo referido a la destrucción de empleo. Una de las principales razones es que la paralización de actividades no alcanzaba a los servicios esenciales, cuya satisfacción se encomienda a las administraciones públicas.

\section{El trabajo durante el confinamiento}

La restricción de la libertad de movimiento durante el estado de alarma, no supuso una paralización total de la vida económica, industrial y empresarial. Es cierto que el Real Decreto-Ley 8/2020 suspendió temporalmente la actividad en algunos sectores, pero el resto podía continuar operando. Sin embargo, para frenar la expansión del virus, el gobierno consideró razonable priorizar el teletrabajo sobre el trabajo presencial donde fuera posible (Cruz Villalón, 2020: 416-419). Esa modalidad, que en el ordenamiento español se enmarca en el denominado trabajo a distancia - el teletrabajo se desarrolla principalmente por medios telemáticos, mientras que el trabajo a distancia es genéricamente el que se realiza fuera de dependencias empresariales-, se regula en el artículo 13 del Estatuto de los Trabajadores, ${ }^{9}$ que proporciona las reglas generales $y$, en principio, exige un acuerdo escrito entre el empresario y el trabajador en orden a admitir el teletrabajo. Asimismo, ese precepto contempla pautas específicas dirigidas a proteger los derechos de los trabajadores.

9. Para más información, véase no anterior. 
Sin embargo, el contexto provocado por el covid-19 no facilitó el cumplimiento de todas esas reglas y limitaciones, porque el teletrabajo no fue producto de una previa y apropiada planificación, sino de una decisión de emergencia en un contexto excepcional, y ni siquiera fue fruto de una voluntad de empresarios y trabajadores, sino que derivó de una recomendación — cercana a la imposición- de los poderes públicos. De ahí que el artículo 13 del Estatuto de los Trabajadores debiera ser flexibilizado, porque el teletrabajo durante el confinamiento tuvo su origen en una necesidad, ya que constituía la única opción posible para la continuidad de muchos negocios, y tanto empresarios como trabajadores debieron adoptar esa modalidad ante la ausencia de otras opciones más satisfactorias, ya que las alternativas consistían en medidas temporales de ajuste de empleo, sin descartar posibles extinciones de contratos. A la postre, el propósito consistía en facilitar, por un lado, la continuidad de la actividad empresarial durante el estado de alarma y, por otro, una inmediata reanudación de la dinámica normal una vez finalizado. ${ }^{10}$

Así, no es de extrañar que el Real Decreto-Ley $8 / 2020^{11}$ incluyera reglas particulares para el teletrabajo, pero con carácter coyuntural, ya que no implicaban una modificación del artículo 13 del Estatuto de los Trabajadores y, por tanto, no se incorporaban como parte del régimen jurídico estructural del teletrabajo, sino que ligarían su vigencia y aplicabilidad a la extensión temporal de los efectos del covid-19. Así sucedía, en particular, con la prevención de riesgos laborales, ya que:

Con el objetivo de facilitar el ejercicio de la modalidad de trabajo a distancia en aquellos sectores, empresas o puestos de trabajo en las que no estuviera prevista hasta el momento, se entenderá cumplida la obligación de efectuar la evaluación de riesgos, en los términos previstos en el artículo 16 de la Ley 31/1995, del 8 de noviembre, de Prevención de Riesgos Laborales, con carácter excepcional, a través de una autoevaluación realizada voluntariamente por la propia persona trabajadora (artículo 5, último párrafo, del Real Decreto-Ley 8/2020).

Ahora bien, el teletrabajo se configuraba como una opción preferente, pero no estrictamente como una exigencia legal, ya que no se acomodaba bien a todas las

10. Los dos primeros párrafos del artículo 5 del Real Decreto-Ley 8/2020 disponían lo siguiente: «Las medidas excepcionales de naturaleza laboral que se establecen en la presente norma tienen como objetivos prioritarios garantizar que la actividad empresarial y las relaciones de trabajo se reanuden con normalidad tras la situación de excepcionalidad sanitaria. En particular, se establecerán sistemas de organización que permitan mantener la actividad por mecanismos alternativos, particularmente por medio del trabajo a distancia, debiendo la empresa adoptar las medidas oportunas si ello es técnica y razonablemente posible y si el esfuerzo de adaptación necesario resulta proporcionado. Estas medidas alternativas, particularmente el trabajo a distancia, deberán ser prioritarias frente a la cesación temporal o reducción de la actividad».

11. Para más información, véase bit.ly/2J8X2tk. 
actividades empresariales, industriales o comerciales. En efecto, muchos sectores no se vieron afectados por la suspensión de actividades durante el estado de alarma, principalmente la industria, donde el trabajo presencial no siempre es sustituible por trabajo a distancia. En estos casos, no se impuso una preferencia por el teletrabajo, sino que se admitió la prestación de servicios presencial, pero con condiciones ad $h o c$, diferentes de las ordinarias. En particular, la normativa de emergencia durante este período facilitaba una reconfiguración de las condiciones de trabajo, sobre todo relativa a la jornada y las funciones, para adaptarse a la nueva situación. Esas medidas dependían de cada entorno, y resultaron más o menos intensas en atención al nivel de producción que podía mantenerse, de modo que determinados sectores continuaron sin necesidad de grandes ajustes, mientras que en otros las condiciones de trabajo se vieron notablemente alteradas (por ejemplo, en algunos ámbitos de la Administración Pública). ${ }^{12}$ Ahí, donde estas adaptaciones no resultaron suficientes, fue necesario adoptar medidas más gravosas, como reducciones de jornada con disminución proporcional del salario. Como se verá, en estas situaciones el gobierno intervino para mejorar la acción protectora del desempleo y garantizar ingresos sustitutivos a los trabajadores afectados.

Desde luego, todas estas variaciones sobrevenidas de las condiciones de trabajo, no planificadas y seguramente tampoco queridas ni por empresarios ni por trabajadores, han provocado un impacto notable en las dinámicas familiares (Rodríguez Escanciano, 2020: 455-462). El artículo 37 del Estatuto de los Trabajadores concede al trabajador el derecho a solicitar, y ver aceptadas, ciertas adaptaciones o modificaciones del tiempo de trabajo para poder atender responsabilidades familiares. Esas reglas fueron complementadas durante el estado de alarma por otras más coyunturales contenidas en el artículo 6 del Real Decreto-Ley 8/2020, que ampliaba los derechos de conciliación cuando el trabajador podía demostrar nuevas necesidades familiares provocadas por el covid-19, entre las que se mencionaba el cierre de guarderías, de centros educativos o el cese (temporal o definitivo) de la actividad de los cuidadores profesionales de personas dependientes, situaciones en las que el trabajador debía asumir, directamente, las labores de atención con la consiguiente dificultad para cumplir sus obligaciones laborales con la misma diligencia (Aragón Gómez, 2020: 45-57).

En estos casos, la norma remitía a un acuerdo entre empresario y empleado en orden a implementar una medida proporcional, que permitiera compatibilizar el trabajo con las nuevas responsabilidades familiares (Gala Durán, 2020: 50-55). Para esto, se sugería un catálogo de posibilidades:

12. Por ejemplo, Navarra: Decreto-Ley $1 / 2020$ del 18 de marzo, disponible en bit.ly/2V9GqUR, y Ley Foral 6/2020 del 6 de abril, disponible en bit.ly/3fAGXsp. 
Cambio de turno, alteración de horario, horario flexible, jornada partida o continuada, cambio de centro de trabajo, cambio de funciones, cambio en la forma de prestación del trabajo, incluyendo la prestación de trabajo a distancia, o en cualquier otro cambio de condiciones que estuviera disponible en la empresa o que pudiera implantarse de modo razonable y proporcionado, teniendo en cuenta el carácter temporal y excepcional de las medidas contempladas en la presente norma, que se limita al período excepcional de duración del covid-19 (Casas Baamonde y Rodríguez-Piñero, 2020: 320-325).

Conviene tener presente que las medidas descritas en este apartado no quedaron limitadas temporalmente a la duración del estado de alarma, sino que originalmente se contemplaba su continuidad durante el mes siguiente a su finalización, plazo que se extendería en dos meses adicionales tras el Real Decreto 15/2020 de 21 de abril, ${ }^{13} \mathrm{y}$ que se ha seguido ampliando hasta 31 de enero de 2021. Por consiguiente, estas medidas coyunturales han dilatado su aplicación en el tiempo, y algunas ellas despliegan efectos a más largo plazo, ya que la «nueva normalidad» no ha permitido reanudar la actividad económica y empresarial a pleno rendimiento. De ahí que el gobierno y los agentes sociales hayan alcanzado varios acuerdos para prolongar los efectos de alguna de esas medidas más allá de esos tres meses, principalmente en relación con la suspensión de contratos y la reducción de jornada en los términos que se desarrollan a continuación.

\section{Prohibición de despidos y suspensión de contratos (ERTE)}

En el contexto de lo laboral, uno de los principales propósitos del gobierno durante el estado de alarma consistía en evitar la destrucción de empleo, que previsiblemente se produciría por la drástica disminución de la actividad económica, ya fuera debido a la suspensión de actividades presenciales o a las restricciones a la movilidad. Ese objetivo se plasmó en el artículo 2 del Real Decreto-Ley 9/2020 del 27 de marzo, que introdujo lo que se ha dado a conocer como «prohibición de despidos», y que sustancialmente consiste en no considerar como razones justificativas del despido la fuerza mayor o las causas económicas, organizativas, técnicas o de producción cuando sean producto de la situación generada por el covid-19. No está claro si se trata exactamente de una prohibición de despido o más bien de la exclusión como justa causa de esas razones. Los tribunales habrán de pronunciarse sobre la calificación que corresponda, ya que la nulidad (que viene aparejada a la vulneración de un derecho fundamental) exige la readmisión obligatoria, mientras que la improcedencia (un despido sin causa o vulnerando las exigencias formales) conduce - a elección normalmente del

13. Para más información, véase bit.ly/2JbloCI. 
empresario- a la readmisión o a la extinción del contrato con una indemnización más alta que la fijada en situaciones de despido procedente por causas objetivas. ${ }^{14}$

Sea como sea, está claro que tiene lugar una restricción de las facultades empresariales que, a modo de compensación, venía acompañada de una mayor facilidad para adoptar medidas de flexibilidad interna y, en particular, tanto reducciones de jornada como suspensiones de contratos más apropiadas para proteger el empleo, y que figuran entre las alternativas que ofrecen las directrices que proporcionó la Organización Internacional del Trabajo para afrontar esta situación (Servais, 2020). ${ }^{15}$ En efecto, la emergencia sanitaria provocó que muchas actividades económicas se paralizaran o que el volumen de negocio disminuyera drásticamente, lo que exigía medidas de ajuste laboral. La amenaza de despidos llevó a actuar al gobierno con el propósito de que las empresas pudieran recurrir eficazmente a un mecanismo que les permitiese transitar por esta complicada coyuntura, sin necesidad de recurrir a decisiones traumáticas que implicasen destrucción de empleo.

Concretamente, las reglas de los denominados expedientes de regulación temporal de empleo (ERTE) fueron adaptadas a este contexto de emergencia y, con ese fin, el artículo 22 del Real Decreto-Ley 8/2020 consideró que la pandemia había dado lugar a una causa específica de fuerza mayor (Beltrán, 2020: 440-445). Conviene precisar que el artículo 47 del Estatuto de los Trabajadores faculta a la empresa a tomar determinadas medidas laborales cuando concurra fuerza mayor, pero podían suscitarse dudas sobre el encaje en ese precepto de las situaciones relacionadas con el covid-19. El Real Decreto-Ley 8/2020 despejó cualquier incertidumbre y amplió el radio de acción de la fuerza mayor, causa, por cierto, de que no podían invocar en esos primeros albores del estado de alarma las empresas privadas de sectores considerados esenciales (centros sociosanitarios), si bien esa limitación fue suprimida tras el Real Decreto-Ley 15/2020 del 21 de abril. ${ }^{16}$

Ahora bien, la adopción de medidas de ajuste laboral debido a fuerza mayor no se produce por la mera voluntad o decisión del empresario, sino que exige la intervención de la Administración Pública con competencias en materia laboral. Así sucede con carácter general, y también en este particular contexto del covid-19, que no exime a los empresarios de la prueba acerca del problema en sí y de su relación con la pandemia, de manera que las medidas propuestas y, en particular, las reducciones de jornada y las suspensiones de contrato - u otras al margen del despido- deben contribuir a aliviar las cargas empresariales con el fin de permitir una pronta reanu-

14. Para más información, véase Real Decreto-ley 9/2020, de 27 de marzo, disponible en bit.ly/39bymvg. 15. Para más información, véase el sitio web de la propia Organización Internacional del Trabajo, disponible en bit.ly/3fCPISI.

16. Para más información, véase bit.ly/2 $V_{5} \mathrm{pdMl}$. 
dación de la actividad productiva sin pérdida de puestos de trabajo. La peculiaridad consiste en que el Real Decreto-Ley 8/2020 flexibilizó el procedimiento general para adaptarse a la emergencia provocada por el coronavirus. Con este fin, la Administración Pública (el Ministerio de Trabajo o el organismo de la comunidad autónoma correspondiente con competencias en materia laboral) había de verificar la existencia de fuerza mayor en los cinco días siguientes a la solicitud de la empresa. Asimismo, la simplificación general del procedimiento venía acompañada de una reducción de costes para las empresas, ya que aquellas con menos de 50 trabajadores se veían exentas de contribuir a la seguridad social por los trabajadores afectados, mientras que el resto disfrutaba de una reducción de cotizaciones del $25 \%$.

Junto a la fuerza mayor, las empresas también podían fundamentar estas medidas de ajuste laboral en causas económicas, organizativas, técnicas o de producción. Estas causas se recogen con carácter general en el Estatuto de los Trabajadores y su adopción no requiere la autorización de la Administración Pública, sino la previa información y consulta con los representantes de los trabajadores. Sin embargo, el estado de alarma dificultaba el respeto a esos derechos de información y consulta, lo que motivó, asimismo, su flexibilización (artículo 24 del Real Decreto-Ley 8/2020), con reglas que reducían los plazos generales ( 7 días en lugar de los 15 o 30 ordinarios según el tamaño de la empresa) y que identificaban a los interlocutores válidos por parte de los trabajadores en empresas que, por su pequeño tamaño (menos de 10 trabajadores), no cuentan con representantes unitarios elegidos en las pertinentes elecciones. En estos casos, la representación de los trabajadores podía ser asumida incluso por tres trabajadores designados por sus compañeros para cumplir con el encargo.

Esa mayor permisividad para la adopción de las medidas debía venir acompañada de un compromiso empresarial con el mantenimiento del empleo, de forma que no cabía una reducción de plantilla durante los seis meses siguientes a la reanudación de la actividad, con alguna excepción en ciertos sectores, por ejemplo, el artístico, donde la función o evento podría haber sido objeto de cancelación. ${ }^{17}$ Además, el incumplimiento de las exigencias legales y, por supuesto, el fraude para disfrutar de esta flexibilización o de las ventajas correspondientes, daba lugar a las pertinentes responsabilidades administrativas.

Los contratos temporales suscitaban una problemática particular, ya que muchos de ellos podían finalizar durante el estado de alarma y, en concreto, durante la paralización forzosa de ciertas actividades impuesta normativamente. Para evitar ese efecto, el gobierno decidió interrumpir la duración de esos contratos en tanto se encontraran suspendidos por una de las vías mencionadas con anterioridad (fuerza ma-

17. Para más información, véase DA 14. ${ }^{a}$ del Real Decreto-Ley 11/2020, disponible en bit.ly/33j1JYL. 
yor o causas económicas, organizativas, técnicas o de producción).$^{18}$ En cierto modo, la ley creó una especie de paréntesis en la duración de los contratos temporales, de modo que no podían llegar a término durante el período de suspensión, sino que "hibernaban" durante el tiempo de suspensión y se reanudaban una vez finalizado este. Asimismo, esta ventaja se extendió a los profesores universitarios y a los investigadores con un contrato no indefinido. ${ }^{19}$

En un primer momento, todas estas medidas limitaban sus efectos al estado de alarma y debían desaparecer una vez concluido. Sin embargo, ese particular contexto se prolongó mucho más de lo previsto y sus consecuencias también fueron más graves de lo inicialmente anticipado. De ahí que las medidas coyunturales, y pretendidamente de muy corta duración, extendieron en el tiempo su vigencia, hasta el punto de que, durante el estado de alarma, se contempló que sus efectos debían perdurar en la llamada "nueva normalidad". En este sentido, el Real Decreto-Ley 18/2020 del 12 de mayo dejó claro que esta regulación de emergencia debía continuar operando como mínimo hasta el 30 de junio ${ }^{20}$-aunque posteriormente algunas de esas medidas, como los efectos de los ERTEs, se han extendido hasta el 31 de enero de 2021- ${ }^{21}$, y que el tránsito de esta legislación de crisis a la estructural no debía producirse de forma abrupta, sino que debía atenderse a las circunstancias. En este sentido, una vez constatado que no cabía una reanudación de la actividad en las mismas condiciones previas al ERTE, se admitió un retorno gradual de los trabajadores a sus puestos, de modo que la decisión de retomar el ritmo ordinario por parte de una empresa, que se había visto obligada a suspender total o parcialmente su actividad, no debía suponer la vuelta de todos los trabajadores simultáneamente, ni tampoco en sí misma el final del ERTE, sino que únicamente se incorporarían a su puesto los trabajadores que el empresario entendiera imprescindibles en cada momento visto el volumen de actividad. No obstante, estas reglas más ventajosas $-\mathrm{y}$ con mayor coste para el erario público- se condicionaban al cumplimiento de una serie de requisitos y, en particular, a que la empresa no tuviera su domicilio fiscal en un paraíso fiscal, a que no repartiera dividendos y al compromiso de no despedir durante seis meses.

Desde la perspectiva del trabajador, el ERTE supone la posibilidad de disfrutar de prestaciones por desempleo para sustituir los ingresos que dejan de percibirse por la reducción de jornada o la suspensión del contrato, en los términos que se desarro-

18. Para más información, véase el artículo 5 del Real Decreto-Ley 9/2020, disponible en bit. ly/2HBPgrs.

19. Para más información, véanse las disposiciones adicionales 12 y 13 del Real Decreto-Ley 11/2020, disponibles en bit.ly/363Rzgr.

20. Para más información, véase el Real Decreto-ley 18/2020, de 12 de mayo, disponible en bit. ly/2J9gZAB.

21. Para más información, véase el Real Decreto-ley 30/2020 del 29 de septiembre. 
llarán en un apartado posterior. Y no conviene olvidar que estas medidas de carácter estatal han sido complementadas por las comunidades autónomas que, con el objetivo de proteger el empleo y reactivar la economía, iniciaron actuaciones de variada índole, pero dirigidas en particular a proporcionar financiación a las empresas, a adaptar los planes de empleo a esta situación excepcional ${ }^{22}$ y a conceder ayudas para contribuir a la creación de empleo. ${ }^{23}$

\section{Permiso retribuido excepcional para trabajadores de actividades no esenciales}

Como se dijo, el 30 de marzo las restricciones a la movilidad de la población se intensificaron al declararse un confinamiento estricto, que no solo afectaba a las personas como individuos, sino también como trabajadores, ya que el Real Decreto-Ley 10/2020 suspendió todas las actividades no esenciales hasta el 9 de abril. ${ }^{24}$ Obviamente, el teletrabajo estaba permitido, pero no así el trabajo presencial, salvo el vinculado a servicios básicos y el que debía prestarse en sectores esenciales, además de determinadas labores de seguridad y mantenimiento necesarias para garantizar una correcta reanudación de actividades tras esas dos semanas de paralización (altos hornos).

Cierto es que la lista de actividades esenciales era ya de inicio bastante extensa, y que superaba la veintena. Entre ellas, cabe mencionar todas las vinculadas a la cadena de abastecimiento del mercado y al funcionamiento de los centros de producción de bienes y servicios de primera necesidad, incluyendo alimentos, bebidas, alimentación animal, productos higiénicos, medicamentos, productos sanitarios o cualquier producto necesario para la protección de la salud; las actividades de hostelería y restauración para la entrega a domicilio; tanto la producción como distribución de material y equipamiento médico-sanitario; los servicios de transporte; los centros y establecimientos sanitarios; prensa (incluida la venta); distribución y comercialización de luz, agua y gas; servicios financieros; empresas de telecomunicaciones y servicios informáticos; asesoramiento jurídico; o los servicios de limpieza, mantenimiento, reparación de averías urgentes y vigilancia. Era una lista de carácter abierto que posteriormente fue ampliada a otros sectores, como determinados servicios de

\footnotetext{
22. Para más información, véase el Decreto-Ley (Andalucía) 10/2020 del 29 de abril, disponible en bit. ly/303xrRT.

23. Para más información, véase Decreto-Ley (Cataluña) 16/2020 del 5 de mayo, disponible en bit. ly/3fHr2bV.

24. Para más información, véase el Real Decreto-ley 10/2020, de 29 de marzo, disponible en bit. ly/3pYXqLU.
} 
cuidados a personas ${ }^{25} \mathrm{y}$ de protección de víctimas de violencia de género. ${ }^{26}$

La paralización obligatoria de la actividad, ordenada legalmente, en este caso no se articuló a través de una suspensión de contratos por fuerza mayor de uno de esos ERTE mencionados en el apartado precedente, sino que el gobierno decidió crear un permiso retribuido durante esa particular circunstancia y, por tanto, hasta el 9 de abril. En efecto, se trataba de una situación obligatoria tanto para trabajadores como para empresarios, de modo que el contrato permanecía vigente, la obligación de pago de salario se mantenía, pero el trabajador no podía acudir a su empleo. No obstante, era un permiso retribuido calificado explícitamente como recuperable, de modo que las horas no trabajadas en ese período debían recuperarse con posterioridad, aunque no en cualquier plazo, sino hasta el 31 de diciembre de 2020 .

Como es razonable, la norma remite a una negociación entre la empresa y los representantes de los trabajadores con la finalidad de concretar el modo en que esas horas deben recuperarse, por lo que en cada empresa ha podido pactarse una solución distinta y adaptada a sus concretas necesidades. En los mismos términos indicados para los ERTE, en defecto de representantes de los trabajadores elegidos en las correspondientes elecciones, lo que sucede en empresas de pequeño tamaño, el Real Decreto-Ley ofrece pautas para designar a los concretos representantes en esa negociación, por lo que no es posible que el empresario fije unilateralmente los criterios de recuperación de ese tiempo de trabajo no realizado. No obstante, es probable que, en la práctica, se susciten algunas dificultades que exigirán a buen seguro la intervención de los tribunales (Lahera, 2020: 422-429).

\section{La adaptación y mejora de los derechos de seguridad social}

La seguridad social ha jugado un papel decisivo durante la crisis provocada por el covid-19. Debido al gran impacto sobre el empleo, el gobierno decidió adoptar medidas de urgencia no solo en el ámbito estrictamente laboral, sino también en relación con los derechos de protección social, cuyos efectos no solo se circunscribirían al período de vigencia del estado de alarma, sino que se extenderían más allá. Se trata de medidas que inciden en distintas prestaciones, pero donde la protección por desempleo cuenta, como no podía ser de otro modo, con un papel protagonista para paliar la pérdida de retribución debido a las reducciones de jornada, suspensiones de contrato y, eventualmente, extinciones de la relación laboral (Vila Tierno, 2020: 35-43).

En este sentido, la prestación por desempleo fue objeto de una ampliación ex-

\footnotetext{
25. Para más información, véase la Orden $\mathrm{SND} / 310 / 2020$ del 31 de marzo, disponible en bit. ly/2 $V_{5} \mathrm{EDQK}$.

26. Para más información, véase el Real Decreto-Ley 12/2020 del 31 de marzo, disponible en bit. ly/378xllo.
} 
traordinaria para acoger a los trabajadores afectados por un ERTE debido al covid-19, que han podido disfrutar de reglas especiales y más flexibles para acceder a la protección. En particular, en estos casos la ley no exigió a los interesados un período de cotización previo, a diferencia de lo que sucede ordinariamente, donde el solicitante ha de reunir 360 días de cotización en los seis años anteriores al cese en el trabajo. Además, el procedimiento se simplificaba, ya que las prestaciones eran solicitadas directamente por la empresa en lugar de por los propios trabajadores, con el fin de reducir en lo posible procedimientos que exigieran la presencia física de los trabajadores en las oficinas de los servicios de empleo en un contexto de movilidad reducida a consecuencia del confinamiento (razón que también explica la flexibilidad con respecto a la denominada renovación de la inscripción como desempleado, que el interesado debe efectuar periódicamente, pero que durante el estado de alarma no se exigió de forma rigurosa). Asimismo, en último término, conviene destacar que, con carácter general, una vez que el trabajador solicita una prestación por desempleo, las cotizaciones utilizadas con ese fin no pueden volver a computarse a efectos de un futuro derecho, de modo que sería necesario acreditar otros 360 días de cotización para poder recibir desempleo nuevamente. Esa regla fue exceptuada para estas prestaciones de emergencia, de modo que el disfrute del desempleo en esta particular coyuntura no perjudicará el derecho de los beneficiarios a futuras prestaciones. ${ }^{27}$

Además de esa significativa flexibilización de los requisitos de acceso, conviene destacar, desde luego, la ampliación del ámbito subjetivo de la protección por desempleo, a la que se ha permitido acceder a personas que, en condiciones ordinarias, estarían excluidas, o al menos habrían debido cumplir exigencias más intensas que, en la práctica, habrían conducido a la denegación de la solicitud (Pérez del Prado, 2020: 495-502). Gracias a estas normas de emergencia, han podido recibir prestaciones por desempleo los miembros de cooperativas, muchos trabajadores fijos-discontinuos, ${ }^{28}$ los $\operatorname{artistas}^{29} \mathrm{y}$ los empleados de hogar, colectivo que no tiene derecho a desempleo con carácter general, pero que, a tenor del artículo 30 del Real Decreto-Ley 11/2020, ${ }^{30}$ ha disfrutado de una prestación extraordinaria de cuantía equivalente al 70\% de su salario previo, aunque con el límite del salario mínimo interprofesional (31,66 euros diarios o 950 euros mensuales).

Asimismo, se ha dulcificado el propio concepto de situación legal de desempleo, que ha de ser involuntario, lo que supone la exclusión de quienes extinguen volunta-

27. Para más información, véase los artículos 25 a 27 del Real Decreto-Ley 8/2020 del 17 de marzo, disponible en bit.ly/33lzlW2.

28. Para más información, véase los artículos 17, 22, 23 y 25 del Real Decreto-Ley 8/2020 del 17 de marzo bit.ly/3fHsQBJ.

29. Para más información, véase el Real Decreto-Ley $17 / 2020$ del 5 de mayo bit.ly/2KBBNRv.

30. Para más información, véase bit.ly/3nPw7BU. 
riamente el contrato. Sin embargo, durante el estado de alarma se admitió el acceso a la protección por desempleo de los trabajadores que renunciaron o dimitieron de un empleo previo por contar con una oferta en firme de otra empresa, pero que no pudieron incorporarse al nuevo puesto debido a la pandemia. Y se consideró irrelevante la causa de extinción del penúltimo contrato de trabajo, cuando el último se extinguió por voluntad del empleador durante el período de prueba. Como regla general, y para evitar fraudes, la extinción de un contrato durante el período de prueba por voluntad del empresario solo permite disfrutar del desempleo si el anterior contrato finalizó por causa no imputable al trabajador. ${ }^{31}$ En todos estos supuestos, el gobierno tomó en consideración que la paralización de la actividad económica y el confinamiento no permitían verdaderamente buscar otro empleo, de modo que las personas sin ocupación podían encontrarse en serias dificultades económicas, incluso para satisfacer sus necesidades básicas (Rojo, 2020: 387-391).

Contemplando la eventualidad de que la protección por desempleo pudiera resultar insuficiente o que el interesado no tuviera derecho a la prestación pese a esta

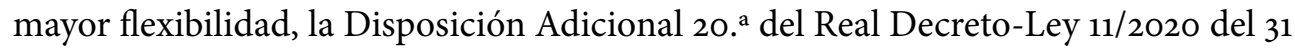
de marzo, ${ }^{32}$ complementada por el artículo 23 del Real Decreto-Ley 15/2020, ${ }^{33}$ permitió, con carácter excepcional, que los trabajadores afectados por ERTEs rescatasen parcialmente sus planes privados de pensiones - que en España son voluntarios y no forman parte de la seguridad social- durante los seis meses siguientes al inicio del estado de alarma, pero con el límite de los salarios dejados de percibir durante esa situación (Taléns Visconti, 2020: 130-138).

Los trabajadores con contrato temporal suscitaban una problemática diferente, ya que si bien pueden acceder a la protección por desempleo en idénticas condiciones que los trabajadores con contrato indefinido, el período previo de carencia supone una dificultad añadida. Es cierto que el gobierno había introducido una regla muy beneficiosa para este tipo de contratos, como se dijo, toda vez que su duración se «congelaba» si habían sido objeto de suspensión durante el estado de alarma por aplicación de un ERTE, de modo que no podían finalizar en tal contexto. Pero no todas las empresas paralizaron su actividad e iniciaron los trámites necesarios para formalizar expedientes de regulación de empleo, lo que implicó, en la práctica, la extinción de muchos contratos de trabajo temporales. Los trabajadores afectados que no acreditaban la cotización pertinente, los ya mencionados 360 días en un período de 6 años anteriores al cese en el trabajo, no contaban con protección por desempleo, ni tampoco con posibilidades reales de encontrar otra ocupación debido al confina-

31. Para más información, véase el artículo 22 del Real Decreto-Ley 15/2020 del 21 de abril, disponible en bit.ly/2JhZxtd.

32. Para más información, véase bit.ly/2JeiRYB.

33. Para más información, véase bit.ly/3nXoKbt. 
miento. Ante esa problemática, el artículo 33 del Real Decreto-Ley 11/2020 creó una prestación extraordinaria de desempleo concebida para estos trabajadores, siempre que el contrato hubiera terminado durante el estado de alarma y su duración hubiera alcanzado como mínimo dos meses. Esta prestación podía percibirse durante un mes y su cuantía se fijó en 430.27 euros. ${ }^{34}$

Esta notable ampliación de la protección por desempleo, mediante la flexibilización de los requisitos generales y la aprobación de nuevas de prestaciones extraordinarias, no cubrió, sin embargo, a toda la población afectada, de modo que muchos trabajadores se vieron privados de sus salarios sin posibilidad de obtener prestaciones por desempleo. Las comunidades autónomas han tratado de cubrir esas lagunas gracias a sus competencias en materia de asistencia social y servicios sociales, y muchas de ellas han creado prestaciones específicas dirigidas a trabajadores con rentas bajas afectados por ERTEs ${ }^{35} \mathrm{y}$, en general, a personas en situación de necesidad. ${ }^{36}$

Al margen de la protección específica para quienes pierden el trabajo, la seguridad social también proporciona prestaciones a quienes no pueden seguir prestando servicios a consecuencia de una enfermedad o accidente, y el covid-19 plantea, en este punto, una problemática particular. En España, la seguridad social trata de forma distinta las denominadas contingencias comunes de las contingencias de origen profesional, ya que estas últimas disfrutan de una tutela reforzada y reciben siempre protección, mientras que, en las primeras, la acción protectora se supedita al requisito de alta y, en caso de enfermedad común, a un previo período de cotización. La covid-19 debería ser considerada como enfermedad común, tanto la enfermedad en sí misma como un eventual confinamiento preventivo para evitar contagios. Sin embargo, esas situaciones vinculadas al coronavirus, incluida la imposibilidad de desplazarse al trabajo ${ }^{37}$ han merecido la calificación de contingencia profesional, lo que implica no solo la exención de esos requisitos de alta y cotización, sino también una mejora en el importe de la prestación de incapacidad temporal, que se eleva al $75 \%$ del último salario frente al $60 \%$ en situaciones de enfermedad común. ${ }^{38}$ En esa misma línea, la

34. Para más información, véase el Real Decreto-Ley 11/2020 del 31 de marzo, disponible en bit. ly/3780TNJ.

35. Así sucede, por ejemplo, en Valencia con el Decreto-Ley 3/2020 del 19 de abril, disponible en bit. ly/3nVnGF8, y Castilla y León con el Decreto-Ley 2/2020 del 16 de abril, disponible en bit.ly/3fAbFSA.

36. Por ejemplo, Baleares con el Decreto-ley 4/2020 del 20 de marzo, disponible en bit.ly/3m9FGLl, Cataluña con el Decreto-Ley 14/2020 del 28 de abril, disponible en bit.ly/3qoSNB5, y el Decreto-Ley 21/2020 del 2 de junio, disponible en bit.ly/39om4jo, y Navarra con el Decreto-ley Foral 3/2020 del 15 de abril, disponible en bit.ly/3lgEnLf.

37. Para más información, véase la Disposición Adicional 21 del Real Decreto-Ley 11/2020, disponible en bit.ly/2JdnySB.

38. Para más información, véase el Real Decreto-Ley 6/2020 del 10 de marzo, disponible en bit. ly/3fCLA5y. 
covid-19 también ha sido considerada como contingencia profesional para el personal sanitario cuando se haya diagnosticado durante el mes siguiente a la finalización del estado de alarma, sin necesidad de demostrar una relación de causalidad con el trabajo, que se presume en estas situaciones. ${ }^{39}$

\section{Una nueva prestación de seguridad social: El «ingreso mínimo vital»}

El protagonismo de la seguridad social para atender las necesidades provocadas por la crisis del covid-19 no se ha limitado a los aspectos mencionados en el apartado anterior y, en concreto, a la mejora de la protección por desempleo y a los necesarios ajustes técnicos para proporcionar una adecuada tutela sanitaria y económica a los más afectados. En verdad, la medida más relevante durante este período ha consistido en la creación de una nueva prestación de seguridad social para las personas en situación de necesidad, que recibe el nombre de "ingreso mínimo vital".

Por supuesto, no es una prestación que se haya gestado durante este particular período de emergencia, ni que conecte con esta problemática de manera inherente, sino que se había planeado con anterioridad. No obstante, la pandemia y sus consecuencias han acelerado notablemente la puesta en marcha de una medida que, a diferencia de la mayoría de las que han visto la luz en esta etapa, no es coyuntural, sino que está concebida con carácter estructural y, por ello, se integra en el catálogo ordinario de la acción protectora de la seguridad social.

En concreto, el ingreso mínimo vital fue creado por el Real Decreto-ley 20/2020 del 29 de mayo, ${ }^{40}$ y tiene como objetivo, en atención a su artículo 1:

Prevenir el riesgo de pobreza y exclusión social de las personas que vivan solas o integradas en una unidad de convivencia, cuando se encuentren en una situación de vulnerabilidad por carecer de recursos económicos suficientes para la cobertura de sus necesidades básicas.

Desde esa perspectiva, no resulta extraño que se configure como una prestación de carácter no contributivo, es decir, una prestación que no exige que la persona beneficiaria haya trabajado y cotizado con carácter previo a la seguridad social.

No es la única prestación de esta naturaleza en el ordenamiento español, pero las anteriores contaban con un ámbito subjetivo mucho más reducido, ya que a ellas podían acceder personas con un grado elevado de discapacidad o mayores de 65 años. El ingreso mínimo vital cuenta con un campo de aplicación mucho más extenso, ya que incluye a personas de entre 23 y 65 años (también de otras edades cuando

39. Para más información, véase el artículo 9 del Real Decreto-Ley 19/2020 del 26 de mayo, disponible en bit.ly/3pVRXp4.

40. Para más información, véase bit.ly/364UFAI. 
concurran razones ligadas a violencia de género, explotación sexual o trata de seres humanos) y, a grandes rasgos, las condiciones para ser beneficiario de la prestación conectan con la falta de recursos suficientes, definidos en atención a unos umbrales de rentas que dependen de si el interesado vive solo o se integra en una unidad de convivencia. En cuanto a la nacionalidad, es una prestación que puede ser reconocida tanto a españoles como a extranjeros, siempre que se encuentren en situación regular y hayan vivido en España durante un año.

Se trata de un marco normativo con cierta complejidad en su aplicación práctica, porque las reglas generales tienen excepciones, porque todavía no se ha aprobado un desarrollo reglamentario que concrete aspectos dudosos y porque es necesaria una coordinación con las comunidades autónomas, que participan en la gestión y algunas de ellas contaban, además, con prestaciones similares.

En relación con el importe, la norma ha optado por configurar una cantidad mínima para el beneficiario que vive solo, pero susceptible de incremento cuando ese beneficiario forme parte de una unidad de convivencia con mayores necesidades. Sin perjuicio de elevaciones al alza en el futuro, de carácter anual, la cuantía mensual del ingreso mínimo vital durante 2020 es de 461,50 euros (5.538 euros anuales), pero puede elevarse en atención al número de convivientes y sus concretas circunstancias hasta 1.015 euros mensuales, amén de la posibilidad de percibir un complemento adicional en caso de familias monoparentales.

Es conveniente destacar que el ingreso mínimo vital no se limita únicamente a proporcionar una prestación económica, sino que pretende también evitar la exclusión social de estas personas en situación de necesidad, de modo que entre sus objetivos se encuentra el de mejorar las oportunidades de carácter social y laboral y, por ello, deben implementarse acciones de mejora de la ocupabilidad y de la inclusión social para los beneficiarios. Así, no sorprende que estos beneficiarios hayan de encontrare inscritos como demandantes de empleo.

En fin, se trata de una prestación que no tiene una duración limitada o predefinida en el tiempo, sino que será percibida por los beneficiarios, en condición de derecho subjetivo, en tanto persista la situación de vulnerabilidad, aunque no necesariamente siempre en el mismo importe, ya que los cambios sobrevenidos en las circunstancias del beneficiario o de su unidad de convivencia pueden afectar tanto al mantenimiento del derecho como a la determinación del importe. Esta prestación, que entró en vigor el 1 de junio de 2020, ya ha sido solicitada por más de medio millón de personas, aunque la tramitación administrativa de estas primeras solicitudes no ha finalizado, de modo que los datos son preliminares y todavía no se dispone de información para obtener conclusiones sobre la efectividad de la medida y su eventual impacto en el empleo. 


\section{Reglas sectoriales y colectivos particulares}

Junto a las medidas de carácter más general, la situación de emergencia derivada del covid-19 motivó actuaciones más concretas para resolver problemas suscitados en determinados sectores. En el ámbito específico de lo laboral y la seguridad social, seguramente el contexto más afectado fue el empleo público, con particular incidencia en el personal sanitario. La pandemia, desde luego, puso a prueba la capacidad y la fortaleza del sistema público de salud y, en determinados momentos, los medios materiales y humanos no resultaron totalmente óptimos para combatir los efectos del covid-19. De ahí que no resulte extraña la adopción de medidas anómalas como, por ejemplo, la flexibilización de los procedimientos para contratar personal sanitario, ${ }^{41}$ que permitió reclutar a personas que todavía no habían obtenido el título necesario para poder realizar las tareas correspondientes, incluso a estudiantes durante el último año de su formación ${ }^{42}$ así como a sanitarios extranjeros sin seguir todos los trámites que normalmente se exigen para personas que proceden del exterior de la Unión Europea. ${ }^{43}$ Todo esto, sin olvidar la extensión de los contratos de los médicos residentes ${ }^{44}$ cuyos procesos de evaluación fueron pospuestos durante el confinamiento, ${ }^{45} \mathrm{y}$ de la vuelta a la actividad de personal sanitario ya jubilado (permitiéndose la compatibilidad del salario con la pensión de jubilación para incentivar su aceptación) ${ }^{46}$ ya que todos ellos resultaban necesarios en esa situación de emergencia sanitaria.

Las medidas de carácter laboral que han afectado al sector sanitario o de cuidados durante la pandemia, no se han circunscrito a esa vertiente del reclutamiento o ampliación de plantilla, sino que han repercutido notablemente en las condiciones de trabajo, ya que el gobierno concedió poderes extraordinarios a los empleadores en ese ámbito para garantizar la atención de los usuarios (ancianos, víctimas de violencia de género, discapacitados y enfermos). Entre esas facultades, sin duda destacan las facilidades para imponer cambios de funciones o movilidad geográfica y, en

41. Para más información, véanse las Órdenes $\mathrm{SND} / 232 / 2020$ del 15 de marzo, disponibles en bit. ly/3leiquI, y 319/2020 del 1 de abril, disponibles en bit.ly/378zWeK. En el ámbito autonómico también se encuentran ejemplos en la misma línea, como el Decreto-Ley 6/2020 del 1 de abril de Baleares, disponible en bit.ly/374PoKi.

42. Para más información, véase la Orden SND/295/2020 del 26 de marzo, disponible en bit. ly/2Ji7AGM.

43. Reglas que también fueron flexibilizadas por alguna comunidad autónoma, como Extremadura con el Decreto-Ley 5/2020 del 3 de abril, disponible en bit.ly/3m9edtt.

44. Para más información, véase la Orden $S N D / 319 / 2020$ del 1 de abril, disponible en bit.ly/39l28O7. 45. Para más información, véase la Orden SND/346/2020 del 15 de abril, disponible en bit.ly/3fyGFCz. 46. Para más información, véase la Disposición Adicional 15 del Real Decreto-Ley 11/2020, disponible en bit.ly/364xAOI. 
definitiva, menores trabas para la reorganización interna que permitiera adaptarse a las circunstancias cambiantes en un período tan convulso. ${ }^{47}$ Obviamente, este incremento de la flexibilidad a favor del empleador, que afectaba incluso a las reglas sobre descansos, vacaciones y podía suponer un retorno a la actividad presencial de quienes estuvieran realizando teletrabajo, implicaba un perjuicio para los trabajadores, $y$ colisionaba con sus derechos de conciliación tanto de la vida laboral como familiar, pero se consideraba que el interés general justificaba esos sacrificios durante un período marcado por necesidades extraordinarias. La única excepción que contemplaba la norma se refería a las trabajadoras embarazadas, que debían quedar al margen de estos cambios (Sanguinetti, 2020).

Otro de los sectores más afectados por el covid-19 ha sido el judicial, ya que el confinamiento de la población motivó la paralización de los plazos administrativos y, con ello, un importante retraso en la tramitación de los litigios. El fin del confinamiento y del estado de alarma supuso la reanudación de la actividad judicial, servicio esencial que exige rapidez para una adecuada satisfacción de los intereses de los ciudadanos, pero que, en este especial contexto, debió ponerse en marcha de manera gradual y escalonada a través de diversas fases, como diseñó el Real Decreto-Ley 16/2020 del 28 de abril..$^{4}$ El propósito consistía no solo en retomar la actividad, sino en recuperarse progresivamente del retraso acumulado y, además, anticiparse a un eventual aumento de la litigiosidad, que, principalmente, en el orden social seguramente se producirá en relación con los ERTEs. Con ese fin, se adoptaron algunas medidas dirigidas a aumentar la plantilla en términos similares al ámbito sanitario y otras que se centraron en modificar las reglas de jornada de trabajo para permitir la celebración de vistas también en horario de tarde, y no solo de mañana. Estos cambios tuvieron un carácter meramente coyuntural, ya que únicamente estuvieron vigentes hasta que se cumplieron tres meses desde la finalización del estado de alarma el 21 de junio de 2020, por tanto, perduraron hasta el 21 de septiembre). ${ }^{49}$

Al margen del empleo público, también cabe destacar las modificaciones operadas en los límites al tiempo de trabajo que afectan a los transportistas, ya que el transporte por carretera ha sido considerado como sector esencial para garantizar el abastecimiento de productos de primera necesidad. Esos límites de jornada vienen establecidos por el derecho de la Unión Europea (Miranda Boto, 2020: 514) y, en concreto, por el Reglamento 561/2006, pero el gobierno español alcanzó un acuerdo

47. Para más información, véase la Orden SND/295/2020 del 26 de marzo, disponible en bit.ly/3mbrovl. 48. Para más información, véase la Orden JUS/394/2020 del 8 de mayo, que contemplaba un retorno a la normalidad en tres fases. La fase 3 se inició el 9 de junio. Véase la Orden JUS/504/2020 del 5 de junio, disponible en bit.ly/3m7cMLT.

49. Para más información, véase el Real Decreto-Ley 16/2020 del 28 de abril, disponible en bit. ly/3nVC4gD. 
con la Comisión Europea para permitir, durante el estado de alarma, que las reglas sobre la jornada máxima diaria, sobre el descanso entre jornadas y sobre el descanso semanal, pudieran ser exceptuadas, de modo, por ejemplo, que la jornada máxima diaria se incrementase de 9 a 11 horas, el descanso diario se redujese de 11 a 9 horas $o$ que el tiempo de descanso semanal pudiera disfrutarse en el propio vehículo (con las oportunas cautelas, como la necesidad de que estuviera adecuadamente equipado)..$^{\circ}$

En esa misma línea de garantía del abastecimiento de productos básicos, el gobierno también debió afrontar las dificultades a las que se enfrentaba el sector agrícola, ya que la mano de obra disponible para afrontar los diversos procesos de recolección de frutas y verduras era muy escasa debido al confinamiento. Así, no es sorprendente que, con carácter urgente y extraordinario, se aprobasen medidas para facilitar el reclutamiento, ${ }^{51}$ y que se dirigían prioritariamente a quienes se encontraban percibiendo prestaciones por desempleo a resultas de la suspensión de su contrato tras un ERTE. En efecto, el gobierno pretendía que los afectados por la pandemia y el confinamiento, que temporalmente no podían prestar servicios en su trabajo habitual, se ocupasen de esas tareas agrícolas y, como incentivo, permitía compatibilizar las prestaciones por desempleo que se estaban percibiendo con los salarios que derivasen de esa nueva actividad en el campo. Esta medida se limitó inicialmente en el tiempo hasta el 30 de junio, pero fue extendida hasta el 30 de septiembre. Además, los extranjeros entre 18 y 21 años que se sumaran a esta posibilidad, disfrutarían de un permiso de residencia de dos años de duración susceptible de renovación por otros dos años. ${ }^{52}$

Asimismo, en relación con los extranjeros, el confinamiento provocó una problemática particular a causa de la suspensión de procedimientos administrativos, que no permitía la renovación de las pertinentes autorizaciones para residir y trabajar. Para evitar incertidumbres, el gobierno prorrogó automáticamente las autorizaciones y tarjetas de identidad - ya que la medida afectaba a extranjeros, a ciudadanos de la Unión Europea y a los miembros de su familia- que expiraban durante el estado de alarma, y lo hizo con cierta generosidad, ya que dicha prórroga se extendería durante los seis meses siguientes a la finalización de esa particular situación. ${ }^{53}$

Por supuesto, los trabajadores autónomos también han sido destinatarios de múltiples medidas de apoyo, ya que la paralización obligatoria de muchas actividades suponía, en la práctica, una privación de ingresos, pero no siempre una reducción sig-

50. Para más información, véanse las Resoluciones de la Dirección General de Transporte Terrestre del 26 de marzo de 2020, disponibles en bit.ly/2V25xJx, y del 14 de abril de 2020, disponible en bit. ly/2J9m5wJ.

51. Para más información, véase el Real Decreto-Ley 13/2020 del 7 de abril, disponible en bit. ly/3pZD1WZ.

52. Para más información, véase el Real Decreto-ley 19/2020, del 26 de mayo, disponible en bit. ly/2 $\mathrm{HFPL}_{3} \mathrm{~S}$.

53. Para más información, véase la Orden $\mathrm{SND} / 421 / 2020$, de 18 de mayo, disponible en bit.ly/3fBCqpV. 
nificativa de gastos. Debido a esto, el gobierno concedió una moratoria en el pago de cotizaciones a la seguridad social y flexibilizó las condiciones para percibir prestaciones por cese de actividad (equivalentes al desempleo de trabajadores asalariados)..$^{54}$ Además, las comunidades autónomas aprobaron normas para conceder ayuda a los autónomos más perjudicados por las consecuencias de la pandemia.55

Finalmente, también conviene destacar que la formación profesional para el empleo debió reorganizarse durante el confinamiento por la suspensión de las actividades formativas de carácter presencial. De ahí que la formación profesional adoptase otros formatos - salvo para el personal ferroviario, contexto en el que sí se autorizó la formación presencial—, ${ }^{56}$ priorizándose la formación a distancia o teleformación y, en concreto, a través de la modalidad de «aula virtual» que había de garantizar una «conectividad sincronizada entre las personas formadoras y el alumnado participante, así como bidireccionalidad en las comunicaciones».57 El retorno a la formación presencial comenzó en junio de 2020 dentro de las fases de la llamada «desescalada»..$^{8}$

\section{El retorno a la «nueva normalidad» a través de un proceso de «desescalada»}

Las cifras de contagios y fallecidos a causa del covid-19 se fueron reduciendo durante el mes de abril, el colapso sanitario se evitó y con ello se debilitó la justificación para el mantenimiento del estado de alarma y para la limitación que supone en los derechos fundamentales de las personas. El gobierno, sin embargo, advirtió que, desde un punto de vista sanitario, resultaba contraproducente una finalización abrupta del estado de alarma y una recuperación completa de las libertades, toda vez que no existía entonces una vacuna frente al covid-19 ni un tratamiento completamente eficaz.

En ese momento, desde la perspectiva del lenguaje, se acuñaron los términos de «nueva normalidad» $\mathrm{y}$ «desescalada», en orden a clarificar que el tránsito desde el confinamiento a la recuperación de las libertades sería gradual («desescalada») y que, una vez concluido ese proceso, la situación no sería la misma que antes de la pan-

54. Para más información, véase el artículo 17 del Real Decreto-Ley 8/2020, disponible en bit. ly/366LFLz, y el artículo 34 del Real Decreto-Ley 11/2020, disponible en bit.ly/3m9JmwD.

55. Verbigracia, Andalucía con el Decreto-Ley 9/2020 del 15 de abril, disponible en bit.ly/33j $\mathrm{P} 73 \mathrm{E}$, Castilla-León con el Decreto-Ley 2/2020 del 16 de abril, disponible en bit.ly/3183kXB, Extremadura con el Decreto-Ley 8/2020 del 24 de abril, disponible en bit.ly/30adYPx, y Navarra con el Decreto-Ley 3/2020 del 15 de abril, disponible en bit.ly/3nXsWbs.

56. Para más información, véase la Orden TMA/379/2020 del 30 de abril, disponible en bit.ly/317Salp.

57. Para más información, véase la Resolución del 15 de abril de 2020, del Servicio Público de Empleo Estatal, disponible en bit.ly/3lgsjtg.

58. Para más información, véase la Resolución del 1 de junio de 2020, del Servicio Público de Empleo Estatal, disponible en bit.ly/366YHIT. 
demia, sino que habrían de respetarse ciertas limitaciones para evitar rebrotes de la enfermedad, de ahí que se aluda a la «nueva normalidad».

El proceso de desescalada comenzó el 4 de mayo de 2020 con la implementación de un plan que constaba de cuatro fases, por las que, progresivamente y de forma asimétrica, irían transitando los distintos territorios de España en atención al impacto del virus en cada uno de ellos. La situación del sistema sanitario, desde luego, constituía un punto de referencia determinante, ya que el paso de una fase a otra dependía, entre otros factores, de que, en caso de eventuales retrocesos, la sanidad pudiera hacer frente a la situación sin riesgo de colapso.

Con esas cautelas, la denominada «fase o», de carácter preparatorio, se inició el 4 de mayo y tuvo una duración de una semana. Durante esa fase, se permitió la apertura de pequeños negocios como, por ejemplo, peluquerías, pero se adoptaron múltiples cautelas, como limitaciones de aforo, mayores medidas de higiene y atención exclusiva mediante cita previa. ${ }^{59}$ Asimismo, la necesaria protección de trabajadores y de clientes conlleva el uso obligatorio de mascarilla y la limpieza frecuente de manos con gel hidroalcohólico. ${ }^{60}$ Todo esto, sin perjuicio de que el teletrabajo seguía siendo considerado como la opción preferente para prestar servicios durante la fase o y $1 .{ }^{61}$

Tras la «fase o», por la que no transitaron algunas islas de Baleares y Canarias (Formentera, La Gomera, El Hierro y La Graciosa) que pasaron directamente a la fase 1 debido a la escasa incidencia del virus, ${ }^{62}$ se inició el proceso real de desescalada, pero no en todas las provincias y comunidades autónomas por igual. Mientras el 11 de mayo algunos territorios (como Madrid y Barcelona) permanecieron en fase o, otros, los menos afectados, pasaron a la fase 1, en la que se permitió la apertura de las terrazas de los bares (no de la zona interior), pero con esas reglas sobre limitación de aforo, distancia social y hábitos de limpieza más intensos.

La fase 2 comenzaría el 18 de mayo en las islas de Canarias y Baleares aludidas, y una semana después, el 25 de mayo, en las provincias y comunidades autónomas de la península con menos incidencia del virus. En la fase 2 ya se admitía una mayor movilidad de las personas, con franjas horarias dedicadas a pasear o hacer deporte ${ }^{63} \mathrm{y}$ cada vez con menos restricciones a la apertura de negocios, si bien discotecas, gimnasios y lugares de ocio con dificultades para mantener la distancia social seguirían restringidos hasta el final del estado de alarma. Todo esto suponía una reincorporación de

59. Para más información, véanse las Órdenes $\mathrm{SND} / 388 / 2020$, del 3 de mayo, disponible en bit. ly/39eT25p, y SND/399/2020 del 9 de mayo, disponible en bit.ly/2KyxJ4u.

6o. Para más información, véase la Orden TMA/384/2020 del 3 de mayo para el sector del transporte, disponible en bit.ly/39dfH29, y Orden JUS/394/2020 del 8 de mayo para el sector de la justicia, disponible en bit.ly/39g6KFf.

61. Para más información, véase la Orden $\mathrm{SND} / 399 / 2020$ del 9 de mayo, disponible en bit.ly/2V99 $4 \mathrm{Tj}$. 62. Para más información, véase la Orden $\mathrm{SND} / 386 / 2020$ del 3 de mayo, disponible en bit.ly/2HBCKrW. 63. Para más información, véase la Orden SND/427/2020 del 21 de mayo, disponible en bit.ly/368alTT. 
los trabajadores, pero de forma gradual, ya que las actividades comerciales no funcionaban a pleno rendimiento y muchos trabajadores permanecían con su contrato suspendido en virtud del ERTE decidido por la empresa en su momento.

La fase 3 se inició el 1 de junio en las islas de Baleares y Canarias mencionadas, ${ }^{64}$ y el 8 de junio en las provincias y comunidades autónomas de la península menos afectadas. ${ }^{65}$ Desde luego, en todas estas fases se mantenía la restricción de movilidad entre unas partes y otras del territorio español para evitar una propagación del virus, y la progresiva reanudación de la actividad económica debía hacer frente a variadas limitaciones, principalmente la de aforo en los establecimientos, imprescindible para garantizar el respeto a la «distancia social».

Tras el término del estado de alarma el 21 de junio de 2020, se han mantenido muchas de las limitaciones adoptadas durante el proceso de desescalada. Las restricciones alcanzan a la entrada en España, no admitida salvo excepciones, algunas de ellas vinculadas al contexto laboral, ya que sí se permite el acceso de quienes deban acceder a España por motivos laborales (trabajadores fronterizos o personal sanitario). ${ }^{66}$ Estos límites se han mantenido hasta el 31 de julio, ${ }^{67}$ sin perjuicio de controles particulares en la frontera con Portugal ${ }^{68} \mathrm{y}$ de reglas específicas para nacionales de países no pertenecientes a la Unión Europea, excepto para ciertos Estados: Argelia, Australia, Canadá, China, Corea del Sur, Georgia, Japón, Marruecos, Montenegro, Nueva Zelanda, Ruanda, Serbia, Tailandia, Túnez y Uruguay ${ }^{69}$ En cualquier caso, la entrada en España exige someterse a determinados controles sanitarios para detectar contagios y prevenir la expansión del virus. ${ }^{70}$

Al margen de esas limitaciones para la entrada en España, conviene poner de manifiesto que tanto el Estado ${ }^{71}$ como algunas comunidades autónomas ${ }^{72}$ han aprobado una normativa específica para regular esta «nueva normalidad», y son reglas que afectan o pueden afectar la dinámica de la prestación de trabajo, como el uso

64. Para más información, véase la Orden SND/458/2020 del 30 de mayo, disponible en bit.ly/3lyIOFT. 65. Para más información, véase la Orden $\mathrm{SND} / 507 / 2020$ del 6 de junio, disponible en bit. ly/3nYDGWQ.

66. Para más información, véase la Orden $\mathrm{SND} / 439 / 2020$ del 23 de mayo, disponible en bit.ly/39im4B5. 67. Para más información, véase la Orden INT/657/2020 del 17 de julio, disponible en bit.ly/2Kyy4nM. 68. Para más información, véase la Orden INT/550/2020 del 21 de junio, disponible en bit.ly/3me17v6. 69. Para más información, véase la Orden INT/595/2020 del 2 de julio, disponible en bit.ly/33ibiHo.

70. Para más información, véase la Resolución del 29 de junio de 2020, de la Dirección General de Salud Pública, Calidad e Innovación, relativa a los controles sanitarios a realizar en los puntos de entrada de España, disponible en bit.ly/33iPD1G.

71. Para más información, véase el Real Decreto-ley 21/2020 del 9 de junio, disponible en bit. ly/2JeSpoG.

72. Por ejemplo, Aragón con la Orden SAN/474/2020 del 19 de junio, disponible en bit.ly/366ZWI3, Castilla-La Mancha con el Decreto 24/2020 del 19 de junio, disponible en bit.ly/3fDmVxJ, y Madrid con la Orden 668/2020 del 19 de junio, disponible en bit.ly/36bxcy5. 
de mascarilla o la distancia social, que no solo tratan de proteger a los clientes, sino también a los trabajadores.

No obstante, una de las mayores preocupaciones del gobierno y los agentes sociales tras el fin del estado de alarma es la reactivación económica y la recuperación de empleo, ya que la destrucción de puestos de trabajo ha sido significativa. España ya se encontraba en una dinámica de ralentización de la economía antes del estado de alarma, con unos 3,2 millones de desempleados en febrero de 2020. Esa cifra se ha incrementado durante esta situación de emergencia, elevándose a 3,8 millones de personas en junio. La recuperación del empleo depende de la reactivación de la economía, que no resulta sencilla en ciertos ámbitos como, por ejemplo, el turismo o la automoción. De ahí que el gobierno y los agentes sociales hayan llegado a acuerdos para introducir estímulos económicos en esos sectores, además de algunos otros. ${ }^{73}$

\section{A modo de conclusión: Potenciales aspectos conflictivos en un futuro cercano}

Como es comprensible, todo este acervo normativo, muy abundante y más si se toma en consideración el escaso período temporal en el que ha sido aprobado, carece del muy conveniente soporte interpretativo que ofrecen los tribunales. No ha habido tiempo material para que se hayan elaborado criterios exegéticos, máxime cuando la actividad judicial se paralizó durante el estado de alarma debido a la suspensión de los plazos procesales. Por consiguiente, la ausencia de pronunciamientos no se debe a la precisión técnica de las normas y a su claridad, sino simplemente a la coyuntura, y es previsible que, en un futuro próximo, esta legislación de urgencia y emergencia deba enfrentarse al examen de los tribunales de justicia (Fernández Avilés, 2020: 19-24).

Por lo pronto, conviene tener presente que la falta de precedentes dificulta las predicciones, porque si bien es cierto que en 2010 el gobierno decretó un estado de alarma (RD 1673/2010) que después fue validada por el TC (STC 83/2016, de 28 de abril), la problemática subyacente era notablemente distinta (un conflicto con los controladores aéreos) y la extensión e intensidad de las medidas y restricciones no resulta comparable en modo alguno. De ahí que cualquier vaticinio deba ser tomado con mucha cautela, ya que, aunque la técnica jurídica no parece haber sido óptima, la emergencia sanitaria ha existido, y con ello el presupuesto jurídico que habilita al

73. Para más información, véase el Real Decreto-ley 25/2020 del 3 de julio, de medidas urgentes para apoyar la reactivación económica y el empleo, disponible en bit.ly/2JiaZp2. También se han aprobado medidas similares en el ámbito autonómico, por ejemplo, en Baleares con el Decreto-ley 8/2020 del 13 de mayo, disponible en bit.ly/2KAKbAM, y Extremadura con el Decreto-Ley 12/2020 del 19 de junio, disponible en bit.ly/2JevFhV. 
gobierno a tomar decisiones extraordinarias. En estos casos, es necesario conceder al Ejecutivo (y en su caso al Parlamento) un margen de apreciación y maniobra de suficiente amplitud por la dificultad que entrañan decisiones en un contexto de esta índole, donde las valoraciones a posteriori no pueden hacer olvidar que, en el momento de tomar la decisión, no se contaba con toda la información de la que después se ha podido hacer acopio.

Por supuesto, esto no atribuye al gobierno una libertad absoluta en ese proceso de toma de decisiones, que debe ajustarse a parámetros de razonabilidad y proporcionalidad en atención a las circunstancias concurrentes, por lo que ese análisis judicial necesariamente se producirá, y previsiblemente en dos planos distintos (sin olvidar, desde luego, que el Tribunal de Justicia de la Unión Europea podría enjuiciar la compatibilidad de las medidas con el derecho de la Unión Europea). En primer lugar, esta normativa deberá ser examinada - por el Tribunal Constitucional- desde la perspectiva de su adecuación a la Constitución. En segundo lugar, los tribunales ordinarios también tendrán que analizar si las concretas actuaciones empresariales se han ajustado al nuevo marco normativo y, además, no será extraño que, en muchos casos, deban dilucidar cuál es la norma aplicable a una concreta situación, ya que coexisten tanto reglas coyunturales como reglas estructurales, y algunas de las coyunturales se contienen en normas reglamentarias que no siempre parecen encajar completamente con disposiciones legales previas y vigentes.

En relación con el respeto a la Constitución, el Tribunal Constitucional deberá precisar, en primer lugar, cuál es la extensión y el contenido del estado de alarma y, por consiguiente, qué poderes o facultades puede legítimamente invocar como propios el Ejecutivo y cuáles se consideran desproporcionados. Es una cuestión no resuelta, pero completamente determinante para enjuiciar el ingente cuerpo normativo de emergencia elaborado a resultas de la pandemia. Por un lado, las comunidades autónomas han sido despojadas de competencias que de ordinario les pertenecen. Por otro, los ciudadanos han visto limitados derechos fundamentales durante un período muy amplio, y tanto la duración como la intensidad merecen una oportuna valoración.

Esas cuestiones, sin embargo, no son las únicas con trascendencia constitucional, sino que el Tribunal habrá de enfrentarse, asimismo, a un problema clásico, que es la utilización, por parte del gobierno, de una norma de urgencia con rango de ley para aprobar determinadas medidas. La Constitución habilita el denominado Real Decreto-Ley únicamente en situaciones de extraordinaria y urgente necesidad. Como regla general, parece evidente que el gobierno estaba legitimado para acudir a ese instrumento durante el estado de alarma, y el Tribunal Constitucional así lo afirmará, sin ningún género de duda. Sin embargo, esto no significa que el gobierno pueda incluir cualquier contenido, medidas o materias en ese tipo de norma. La utilización del Real Decreto-Ley puede resultar compatible con la Constitución, pero su contenido 
concreto, aunque sea parcialmente, podría calificarse como excesivo e impertinente $y$, por tanto, inconstitucional. En verdad, algunas de las medidas incluidas en ese tipo de normas durante el estado de alarma no parecían tener relación con el covid-19 ni ser particularmente urgentes (por ejemplo, la reorganización de la gestión de la seguridad social de los funcionarios públicos).

A los tribunales ordinarios, por su parte, les llegarán litigios de muy diversa naturaleza, algunos difícilmente previsibles en este momento, en el que caben vaticinios, pero muy pocas certezas. La problemática relativa a las fuentes de derecho, a la que se aludió, y la derivada de los ERTEs (existencia o no de causas, posibles sanciones por extralimitación, etcétera), constituirán, a buen seguro, conflictos comunes, pero muchas otras cuestiones merecerán la oportuna intervención judicial, como el modo de recuperación de las horas no trabajadas en virtud del permiso retribuido recuperable al que se aludió en el cuarto apartado. Por su parte, la extensión tras el estado de alarma de muchas medidas laborales (prohibición de despidos o preferencia por el teletrabajo) plantea una interrogante que es necesario resolver, ya que la coexistencia de una regulación coyuntural y una estructural sin el amparo formal del estado de alarma constituye un escenario jurídico desconocido. Es cierto que algunas de esas medidas "prorrogadas" o "extendidas" en esta situación de nueva normalidad se vinculan al disfrute de determinados beneficios (principalmente ERTEs), de modo que es un compromiso que la empresa debe asumir por disfrutar de una ayuda pública, lo que no resulta incompatible con la legislación estructural.

Sin embargo, otras medidas, como la preferencia por el teletrabajo, carecen de un engarce claro en la legislación, en particular si se considera que no es necesario el acuerdo con el trabajador o que pueden reducirse las garantías en relación con la prevención de riesgos laborales, como sucedió durante el estado de alarma. Las normas estructurales y las coyunturales son, en este punto, directamente contradictorias y las fricciones pueden producirse.

Todo esto sin olvidar que las decisiones administrativas en materia de salud pública tienen una repercusión laboral innegable, como sucede con el uso de mascarillas, los hábitos de higiene reforzados o las restricciones a la libertad de movimiento que algunas comunidades autónomas y ayuntamientos pretenden imponer en caso de rebrotes. En este punto, se entremezclan aspectos constitucionales y meramente legales, pero ni está claro que todas las administraciones tengan competencias para tomar esas medidas ni tampoco que resulte jurídicamente lícito limitar determinadas opciones individuales de las personas fuera del estado de alarma, por más que, desde un punto de vista sanitario, pudiera ser razonable. El Tribunal Constitucional habrá de pronunciarse sobre esas cuestiones, pero los tribunales ordinarios deberán resolver problemas concretos de aplicación como, por ejemplo, la licitud de una sanción, inclusive un despido, por la negativa de un trabajador a utilizar mascarilla o a lavarse las manos con la periodicidad establecida. La respuesta no parece evidente si, por 
ejemplo, el trabajador no padece la enfermedad, y menos aún si fuera inmune. La problemática potencial es amplísima y entronca, en ocasiones, con los principios de igualdad y no discriminación, ya que no será infrecuente que las decisiones de contratación o, en su caso, de despido, puedan depender de si el trabajador ha padecido la enfermedad, la está pasando o, en su caso, es inmune.

No obstante, las respuestas concretas demorarán años hasta convertirse en definitivas, por el normal devenir de los plazos judiciales y porque la enfermedad en sí misma parece lejos de ser erradicada. En el momento de escribir estas líneas, se ha publicado la primera sentencia de un juzgado que ha declarado nulo, con obligación de readmisión, el despido de una trabajadora durante el estado de alarma por vulneración de la regla sobre prohibición de despidos. Dicha prohibición existe, pero no está claro que entronque con un derecho fundamental y que su vulneración conlleve la nulidad. El despido ilícito en el ordenamiento español se califica tanto de ordinario como improcedente, y permite al empresario decidir entre la extinción del contrato con derecho a indemnización o la readmisión del trabajador. Este será, sin duda, otro aspecto conflictivo en una larga lista dentro de los próximos meses.

\section{Referencias}

Álvarez García, Vicente (2020). «El coronavirus (covid-19): Respuestas jurídicas frente a una situación de emergencia sanitaria». El Cronista, 86-87: 6-21. Disponible en bit.ly/3hewaoO.

Aragón Gómez, Cristina (2020). Impacto del covid-19 en materia laboral y de Seguridad Social. Madrid: Francis Lefebvre.

Beltrán de Heredia Ruiz, Ignasi (2020). "Covid-19 y expediente de regulación temporal de empleo por fuerza mayor». Derecho de las Relaciones Laborales, 4: 435-449. Disponible en bit.ly/2M8lxbB.

Casas BaAmonde, María Emilia, y Miguel Rodríguez-Piñero y Bravo-Ferrer (2020). «Un nuevo derecho del trabajo en la emergencia. Las medidas laborales y de seguridad social en el estado de alarma declarado por la crisis sanitaria del coronavirus covid-19». Derecho de las Relaciones Laborales, 4: 317-348.

Cruz Villalón, Jesús (2020). "Teletrabajo y coronavirus: De la emergencia a la permanencia». Derecho de las Relaciones Laborales, 4: 416-419. Disponible en bit. ly/38xNtoa.

Fernández Avilés, José Antonio (2020). «¿Es suficiente este derecho laboral excepcional "por aluviones" frente a la pandemia del covid-19?». Revista de Trabajo $y$ Seguridad Social (CEF), 445: 7-26. Disponible en bit.ly/3hh9Bj7.

Gala Durán, Carolina (2020). «Las medidas adoptadas en materia de Seguridad Social y conciliación de la vida laboral y familiar en relación con la crisis del Coronavirus covid-19». La Administración Práctica, 5: 49-62. 
LAHERA Forteza, Jesús (2020). «Flexiseguridad laboral ante la crisis del coronavirus». Derecho de las Relaciones Laborales, 4: 419-429. Disponible en bit.ly/34JjvF9.

Miranda Boto, José María (2020). «¿Esperando a Grouchy? El papel de la Unión Europea en la crisis del covid-19». Derecho de las Relaciones Laborales, 4: 513-517. Disponible en bit.ly/3nQ40RM.

Pérez del Prado, Daniel (2020). «La protección por desempleo ante la crisis del coronavirus». Derecho de las Relaciones Laborales, 4: 491-513. Disponible en bit. ly/3hiBhUW.

Rodríguez Escanciano, Susana (2020). «Medidas para la conciliación de la vida laboral y familiar ante la emergencia sanitaria por covid-19». Derecho de las Relaciones Laborales, 4: 449-472. Disponible en bit.ly/37PhsBD.

Rojo Torrecilla, Eduardo (2020). «Emergencia sanitaria y legislación laboral. ¿Qué respuestas a la crisis? Un primer análisis de la normativa dictada en España». Derecho de las Relaciones Laborales, 4:384-406. Disponible en bit.ly/2JjiopT.

SANGuineti Raymond, Wilfredo (2020). «El derecho del trabajo español de la emergencia sanitaria». Revista General de Derecho del Trabajo y de la Seguridad Social, 56. Disponible en bit.ly/37OwtU6.

Servais, Jean Michel (2020). «El covid-19. ¿Qué nos dice la OIT?». Disponible en bit. ly/2KJZaZp.

TAlÉNs Visconti, Eduardo (2020). «Análisis de las medidas de Seguridad Social adoptadas por el Gobierno de España en relación con la crisis del covid-19». Revista de Trabajo y Seguridad Social (CEF), 445: 121-145. Disponible en bit.ly/3aKVwJB.

Vila Tierno, Francisco (2020). La respuesta normativa a la crisis laboral por el COVID-19. Murcia: Laborum.

\section{Sobre el autor}

Iván Antonio Rodríguez Cardo es profesor titular de la Universidad de Oviedo de España y experto nacional en la European Labour Law Network. Su correo electrónico es rodriguezivan@uniovi.es. (D) https://orcid.org/0000-0003-0721-467X. 
La Revista Chilena de Derecho del Trabajo y de la Seguridad Social es una publicación semestral del Departamento de Derecho del Trabajo y de la Seguridad Social de la Facultad de Derecho de la Universidad de Chile, y que tiene por objetivo el análisis dogmático y científico de las instituciones jurídico-laborales y de seguridad social tanto nacionales como del derecho comparado y sus principales efectos en las sociedades en las que rigen.

\author{
DIRECTOR \\ Luis Lizama Portal \\ EDITOR \\ Claudio Palavecino Cáceres \\ SECRETARIO DE REDACCIÓN \\ Eduardo Yañez Monje \\ SITIO WEB \\ revistatrabajo.uchile.cl \\ CORREO ELECTRÓNICO \\ pyanez@derecho.uchile.cl \\ LICENCIA DE ESTE ARTÍCULO \\ Creative Commons Atribución Compartir Igual 4.o Internacional
}

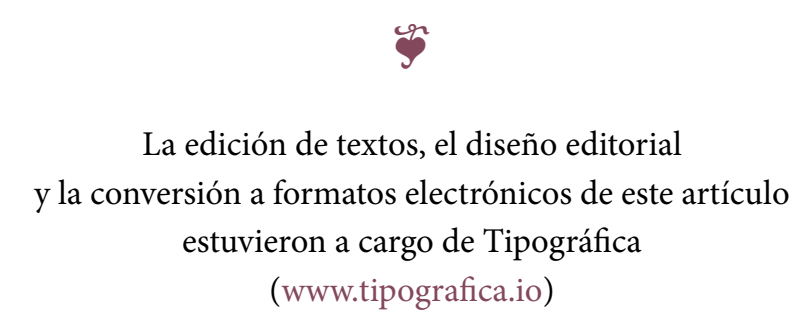

